\title{
Development and Performance Evaluation of an Electric Motor Powered Ginger Washing-Cum-Peeling Machine
}

\author{
G.V. Prasanna Kumar*, C.B. Khobragade, Rakesh Kumar Gupta and Kamran Raza \\ Department of Agricultural Engineering, Assam University, Silchar 788011, Assam, India \\ *Corresponding author
}

\section{A B S T R A C T}

\section{Keywords}

Bleached ginger, Material loss, Nondominated sorting, Peeling efficiency, Rough peeled ginger, Washing efficiency

Article Info

Accepted:

07 January 2019

Available Online:

10 February 2019

\begin{abstract}
A batch type ginger washing-cum-peeling machine was developed and investigated for its use in the production line of bleached dry ginger. The machine used 2 hard nylon brush rollers that rotated at $200 \mathrm{rpm}$ in opposite direction. The rhizomes got lifted and tumbled on the rollers, and the application of jets of water removed the soil and other foreign material from the surface of rhizomes and about $59 \%$ of the total peels. Output capacity of the machine was $13.86 \mathrm{~kg} / \mathrm{h}$ with about $2 \%$ loss of edible material. The machine required one unskilled labourer to feed $3 \mathrm{~kg}$ fresh harvested ginger rhizomes at every 12 minute interval and collect the rough peeled rhizomes after each batch of operation. Use of machine in the production line of bleached dry ginger resulted in the saving of $42.3 \%$ of labour and $46.7 \%$ time involved in manual washing and peeling. Ginger washing-cumpeeling machine is recommended for small processing centres, commercial kitchens and restaurants where there is need of about $3.4 \mathrm{~kg}$ peeled rhizomes/day.
\end{abstract}

\section{Introduction}

Ginger (Zingiber officinale Rosc.) is the underground stem (rhizome) of a perennial herb. It has distinct sharp and hot flavor due to an oily substance called gingerol (Villamor, 2012). It is processed and consumed in various forms such as raw ginger, dry ginger, bleached dry ginger, ginger powder, ginger oil, ginger oleoresin, gingerale, ginger candy, ginger beer, brine ginger, ginger wine, ginger squash, ginger flakes etc. In India, domestic market prefers fresh green ginger for culinary use. Two types of dried ginger, bleached and unbleached, are produced for export purpose (IISR, 2015).

Ginger attains full maturity in 210-240 days after planting. Harvesting is done by loosening the soil and lifting the rhizomes from the soil (Govindarajan, 1982; Weiss, 2002). Care is taken to see that the rhizomes do not cut into pieces during harvest and postharvest handling. First stage in postharvest processing is washing of rhizomes to remove the soil clinging to the surface of rhizome. If washing is delayed, the soil gets dried on the surface of rhizomes. Soil on the 
surface contaminates the rhizomes and makes it unsuitable for consumption (Peter and Zachariah, 2000; Emers, 2012). In conventional washing of ginger, growers use big perforated crates or tubs (Emers, 2012; Ghuman et al., 2014). The rhizomes are put in the perforated crates and are washed using a jet stream of water. The crops have to be regularly shuffled with hand for proper cleaning. This is time consuming and labour intensive task. Pressure washing is efficient and tends to reduce the microbial load (Pruthi, 1992). Traditionally, rhizomes are killed by immersion in boiling water for 10 minutes. This also inactivates enzymatic processes (Sutarno et al., 1999; Weiss, 2002).

In the production of dried ginger, peeling is done in addition to washing to remove the outer skin. Peeling or scraping reduces drying time, and minimizes mold growth and fermentation (Pruthi, 1992). Dry ginger is valued for its aroma, flavour and pungency (Balakrishnan, 2005). Most oil constituents are concentrated below the epidermal tissues. Excessive scraping removes some of the oil constituents, and reduces pungency and aroma quality (Sutarno et al., 1999; Weiss, 2002). In India, rhizomes are peeled only on the flat sides and much of the skin in between the fingers remains intact. The dry ginger so produced is known as the rough peeled or unbleached ginger (IISR, 2015). Jamaica produces clean peeled whole dried gingers (Zachariah, 2008).

Cleaning and drying procedures should be done as fast as possible after harvest to ensure minimum loss from microbial contamination, mold growth and fermentation. Mechanical washers, slicers, and solar or hot air driers help to minimize contamination from dust during postharvest handling operations (Weiss, 2002). Researchers have developed mechanical devices for washing root crops. Ambrose and Annamalai (2013) developed a batch type small washer with holding capacity of $10 \mathrm{~kg}$ for washing root vegetables like carrot and raddish. The washer consisted of a detopper, a stainless steel washing drum, a centre shaft with holes for water spraying and a hand wheel for the manual rotation of drum. The washing drum was provided with matting of various materials and thickness for the effective cleaning of vegetables. The washing and cleaning efficiencies were 97 and $91 \%$ for carrot and 96 and $90 \%$ for raddish, respectively using $3.5 \mathrm{~mm}$ thick plastic matting. Choi et al., (2014) developed a root crop washer that consisted of 2 brushes rolling in opposite direction and a water delivery system. The brushes were operated manually by leg cranking at $6 \mathrm{rpm}$. The machine effectively removed the surface dirt from carrots with minimal damage to greens and skin. Ghuman et al., (2014) reported the development of an electric motor powered root crop washer for potatoes, carrots, radish, etc. The muddy root crops were put inside the root crop washer drum. The drum was then rotated by a motor and water under pressure was supplied in the drum. Due to the rotation of the drum and the continuous supply of water, the soil and clay particles were removed off the root crops. The muddy water fell down through the slits provided in the drum. To remove the dirt and other foreign materials from root crops in large scale processing industries, roll-type cleaners are used. The roll-type cleaners provide a scrubbing action. Emers (2012) reported a barrel washer (Grindstone Farm design) for cleaning beets, rutabagas and turnips. It could also be recommended for washing all root crops.

The mechanical washers developed for the root crops could be used for washing ginger rhizomes as well. However, preparation of dried ginger requires washing as well as peeling. Hand peeling is a skilled and time consuming operation. The skilled labour 
required for the delicate operation is reported to be becoming scarce and costly (Srinivasan et al., 2008). Mechanical devices for peeling of ginger rhizomes have been attempted. The specifications of mechanical rotary drum type washer peelers with a capacity of $15-40 \mathrm{~kg} / \mathrm{h}$ are available for ginger, sweet potato, potato, arrow root, radish and carrot (Bureau of Product Standards, 2008). Agrawal et al., (1987) developed an abrasive brush type ginger peeling machine that consisted of 2 continuous brush belts driven in opposite directions with a downward relative velocity by an electric motor. Brush-belt spacing of $1.0 \mathrm{~cm}$, driving belt speed of $65 \mathrm{rpm}$ (199 $\mathrm{cm} / \mathrm{s}$ ) and 4 to 5 of passes were recommended. The peeling capacity of the machine was $20 \mathrm{~kg} / \mathrm{h}$ with an average peeling efficiency and the meat loss passes, of 82 and $2.7 \%$, respectively, with 4 passes and 75 and $2.2 \%$, respectively with4 passes. Jayashree and Viswanathan (2012) developed a mechanical ginger peeler with a square mesh drum that operated at $40 \mathrm{rpm}$ and peeled $8 \mathrm{~kg}$ fresh rhizomes in 15 minutes. Peeling efficiency and material loss were $55.60 \%$ and $4.68 \%$, respectively.

In the present study, a small capacity mechanical device that simultaneously washes and rough peels ginger rhizomes is developed. Mechanical washer-cum-peeler has the advantage that it can give clean partially peeled rhizomes which can be used for the preparation of rough peeled dry ginger.

Suitable washing and peeling process parameters for the efficient washing and peeling of rhizomes with minimum loss of edible material from the rhizome was determined. Further, feasibility of using the machine as a supplement to the conventional manual washing and peeling for the preparation of bleached dry ginger was studied.

\section{Materials and Methods}

\section{Development of ginger washing-cum- peeling machine}

The ginger washing-cum-peeling machine performs 2 processes simultaneously. The first process is washing. It is accomplished by repeated lifting and tumbling of rhizomes with application of water. This results in the removal of soil and other foreign material from the surface of ginger rhizome. Lifting and tumbling of the rhizomes can be achieved by placing the ginger rhizomes over 2 cylindrical rollers rotating in opposite direction. The second process is peeling. It is accomplished by the abrasive action of rotary brushes against the surface of the ginger rhizome. The rollers with hard nylon brush can provide abrasive action to the surface of rhizome. This results in rough peeling of rhizomes. The ginger washing-cum-peeling machine consists of (i) a washing tank, (ii) brush rollers, (iii) water application system, and (iv) an electric motor and power transmission system. An isometric view of the ginger washing-cum-peeling machine is shown in Figure 1.

The washing tank of $480 \mathrm{~mm}$ length, $320 \mathrm{~mm}$ width and $400 \mathrm{~mm}$ depth was used to hold the ginger rhizomes. The tank was open at the top, bottom and on one lateral side for feeding of rhizomes, flowing of water downwards after washing, and removing rhizomes from the tank after washing and peeling, respectively. A sliding door was provided on the lateral side for closing it during working, and opening it when the rhizomes are to be removed from the machine after washing. The cylindrical brush rollers are provided near the base of the tank to facilitate lifting and tumbling of ginger rhizomes.

The functions of brush rollers are, (i) to facilitate the lifting and tumbling of ginger 
rhizomes in the tank so that all the surfaces of the rhizome are exposed to the jet of water from the perforated pipe, and (ii) to scrape the surface of the rhizome so that the skin is peeled off. These two requirements were fulfilled by selecting 2 cylindrical brush rollers with hard nylon brushes on the circumference. The rollers had plastic core of $90 \mathrm{~mm}$ diameter. The overall diameter and length of the brush rollers was 116 and 600 $\mathrm{mm}$, respectively.

The circumferential thickness of the nylon brushes on the core was $13 \mathrm{~mm}$. The shaft of the roller was of $20 \mathrm{~mm}$ diameter, and it was made of mild steel. The rollers were rotated in opposite direction using a chain drive with idlers. The arrangement of chain drive is shown in Figure 2. The two rollers were provided at a centre to centre distance of 120 $\mathrm{mm}$.

Water application system consists of an electric motor powered centrifugal pump and perforated pipe. Pump had the capacity of $0.27 \mathrm{~kW}$ with rated discharge of $800 \mathrm{~L} / \mathrm{h}$ (maximum discharge head, $18 \mathrm{~m}$ ). Pump shaft was coupled to a $0.54 \mathrm{~kW}$ electric motor with rated speed of $2800 \mathrm{rpm}$. The diameter of suction and discharge pipe is $25 \mathrm{~mm}$. The perforated pipe is placed on the top of tank so that the jet of water falls on the rhizomes to remove the soil and other foreign material.

Three phase induction motor of $1.5 \mathrm{~kW}$ with rated speed of $1410 \mathrm{rpm}$ was used as source of power for the ginger washing-cum-peeling machine. The brush rollers were operated at $200 \mathrm{rpm}$. Two sets of chain drive with total velocity ratio of $7: 1$ between the motor shaft and the drive shaft of the roller was used. An overall view of the ginger washing-cumpeeling machine is shown in Figure 3 and an inside view of the washing tank is shown in Figure 4.

\section{Preliminary trials}

The preliminary trials were conducted in the laboratory for making necessary adjustments in the machine for maximum washing and peeling of rhizomes with minimum loss of edible material. Water was pumped to the washing tank. Water discharge of $13 \mathrm{~L} / \mathrm{min}$ was required to cause the force of jet of water through the perforated pipe for sufficient washing of rhizomes. It was found that rotary speed of brush roller in the range of 150-250 rpm is required to impart sufficient lifting and tumbling to the rhizome for the removal of soil and peels. Further, ginger rhizomes were observed from time to time so that there is minimum loss of edible material along with peel. Batch feeding of $3.0-4.0 \mathrm{~kg}$ fresh rhizomes resulted in uniform washing and peeling. Each batch of rhizome has to be held in the washing tank for a period of 8-16 minutes for maximum washing and peeling. It was observed that lower quantity of rhizomes fed per batch with higher speed of rollers and longer holding time, resulted in better washing and peeling with higher removal of edible material. On the other hand, higher quantity of rhizomes fed per batch with lower speed of rollers and shorter holding time, resulted in poor washing, non-uniform peeling of rhizomes and lower loss of edible material.

\section{Experiment}

The purpose of experiment is to identify the suitable combination of rotary speed of brush rollers, quantity of ginger rhizomes to be fed per batch (batch size) and holding time in machine (machine operating parameters) for achieving maximum washing and peeling efficiency with minimum loss of edible rhizome material. Three levels of rotary speed of brush rollers (150, 200 and $250 \mathrm{rpm})$, batch size $(3.0,3.5$ and $4.0 \mathrm{~kg})$ and holding time (8, 12 and 16 minutes) were considered for the 
experiment. Full factorial design of experiment was conducted with 3 replications for each combination of rotary speed of brush rollers, batch size and holding time.

\section{Procedure}

(i) Fresh harvested ginger (variety, Nadia) rhizomes were collected from a market garden. Pump was started and water was applied at the rate of $13 \mathrm{~L} / \mathrm{min}$. The electric motor of the machine was started. The brush rollers were operated at the specific rotary speed.

(ii) A batch of fresh harvested ginger of weight $W_{1}$ was fed to the washing tank. They were subjected to washing and peeling for a specific period. Just before the completion of holding time, the sliding door of the tank was opened, and the ginger rhizomes were pushed out of the washing tank. The washed and peeled rhizomes were collected.

(iii) The weight of ginger rhizomes collected at the outlet $\left(W_{2}\right)$ was determined using a digital weighing balance.

(iv) Soil and other foreign material if any present on the rhizomes was manually washed using clean water. The weight of completely washed rhizomes (free of soil) was determined $\left(W_{3}\right)$.

(v) The peels on the rhizomes not removed by machine were manually removed using a knife. The weight of completely washed and peeled rhizomes (free of soil and peels) was determined $\left(W_{4}\right)$.

\section{Performance indices and data analysis}

The following 4 indices were developed for the performance evaluation of the ginger washing-cum-peeling machine: (i) Overall efficiency, (ii) Washing efficiency, (iii) Peeling efficiency and (iv) Percent loss of edible material.

They were determined as follows:

Weight of fresh harvested ginger fed to machine per batch $=W_{1}$.

Weight of ginger rhizomes collected at the outlet after machine washing and peeling = $W_{2}$.

Weight of ginger rhizomes after the complete washing by hand $=W_{3}$.

Weight of ginger rhizomes after the complete washing and peeling by hand $=W_{4}$.

$W_{1}=G+T S+T P$

where, $G=$ Weight of ginger rhizomes without any soil and peels on the surface.

$T S=$ Total weight of soil adhered to rhizomes Soil is partly washed away in the machine $(M S)$, and the rest is removed manually by hand $(H S)$.

$T P=$ Total weight of peels on the rhizomes. Peels are partly removed by the machine $(M P)$, and the rest is removed manually by hand $(H P)$.

Total weight of soil adhered to rhizomes, $T S=$ $M S+H S$

where, $M S=$ Weight of soil washed away in the machine.

$H S=$ Weight of soil removed manually by hand.

Total weight of peels on the rhizomes, $T P=$ $M P+\mathrm{HP}$ 
where, $M P=$ Weight of peels removed by the machine.

$H P=$ Weight of peels removed manually by hand.

$$
\begin{aligned}
& W_{2}=G+H S+H P \\
& W_{3}=G+H P \\
& W_{4}=G
\end{aligned}
$$

Overall efficiency $=\frac{\frac{W_{1}-W_{2}}{W_{1}-W_{4}} \times 100}{W_{1}-W_{2}} \times 100$
Washing efficiency $=\frac{W_{1}-W_{8}}{W_{1}-W_{8}} \times 100$
Peeling efficiency $={ }^{\frac{W_{1}-W_{4}}{W_{1}-W_{4}}} \times 100$

As washing and peeling of ginger rhizomes are performed simultaneously,

Overall efficiency $=$ Washing efficiency $\times$ Peeling efficiency

The mechanical operation was accomplished manually to determine the percent loss of edible material during mechanical washing and peeling.

Fresh harvested ginger rhizomes (of weight $W_{1}$ ) from the same lot were collected. They were manually washed to remove all soil and other foreign material. Weight of clean rhizomes $\left(W_{5}\right)$ was noted. The rhizomes were completely peeled using a knife. Care was taken not to remove the edible material from the rhizomes. Weight of the peeled rhizomes $\left(W_{6}\right)$ was noted.

Percent loss of edible material during mechanical washing and peeling

$=\frac{W_{6}-W_{4}}{W_{6}} \times 100$

where, $W_{4}$ is the weight of completely peeled rhizomes after mechanical washing and peeling.
Theoretical percent soil attached on fresh ginger rhizomes $=\frac{W_{1}-W_{s}}{W_{s}} \times 100$

Theoretical percent peel on clean ginger rhizomes $=\frac{W_{5}-W_{6}}{W_{5}} \times 100$

The values of theoretical percent soil attached on fresh ginger rhizomes and theoretical percent peel on clean ginger rhizomes was used for the calculation of percent loss of edible material in all the experiment trials.

Effect of rotary speed of brush rollers, batch size and holding time on washing efficiency, peeling efficiency and percent loss of edible material was studied by analysis of variance.

\section{Identification of the best combination of machine operating parameters}

The best combination of rotary speed of brush rollers, batch size and holding time (machine operating parameters) that resulted in higher washing and peeling efficiencies with lower loss of edible material was identified by nondominated sorting (Deb et al., 2002).

In the present study, washing and peeling efficiencies have to be maximized, and percent loss of edible material has to be minimized. In order to convert it into a problem of minimization of all the performance indices, reciprocal of washing and peeling efficiencies was considered. Steps involved in non-dominated sorting are given below:

$i$. One individual combination of machine operating parameters (rotary speed of brush roller, batch size and holding time), $p$ along with performance indices (washing efficiency, peeling efficiency and percent loss of edible material) was taken up.

ii. The performance indices for this 
combination of machine operating parameters were compared with other combination of machine operating parameters. A set $\left(S_{p}\right)$ of the combination of machine operating parameters that $p$ dominated was generated as per the following definition of dominance:

A combination of machine operating parameters $p$ is said to be dominating another combination of machine operating parameters $q$ if all the performance indices corresponding to $p$ are smaller than or equal to those corresponding to $q$.

iii. The number of combination of machine operating parameters in the set $S_{p}$ was noted.

iv. Steps $i$ to $i i i$ were repeated for each individual combination of machine operating parameters.

$v$. A set of machine operating parameters along with performance indices was generated in the descending order of the number of combination of machine operating parameters they dominated (number of rows in $S_{p}$ ).

Any combination of machine operating parameters can be selected from the generated set of machine operating parameters that represent the trade off between the competing requirements. The combination of machine operating parameters that dominated the maximum number of combination of machine operating parameters was selected as the best combination of machine operating parameters.

\section{Performance evaluation}

Performance evaluation (confirmation experiment) of the ginger washing-cumpeeling machine was conducted at the best combination of rotary speed of brush rollers, batch size and holding time continuously for one hour. The procedure as mentioned above was followed with 5 replications. In the confirmation experiment, only $10 \%$ of the ginger samples were randomly collected for the determination of washing and peeling efficiencies and percent loss of edible material. The average observed value of the initial experiment $\pm C I$ will give the $95 \%$ confidence interval for the average value of washing and peeling efficiencies and percent loss of edible material (Antony and Kaye, 2000). The $C I$ was estimated using the following two equations:

$C I=\sqrt{F_{\left(0.05,1, d f_{\text {error }}\right)} M S S_{\text {error }}\left[\frac{1}{N_{\text {eff }}}+\frac{1}{R}\right]}$

and

$N_{\text {eff }}=\frac{N}{1+d f_{\text {total }}}$

where, $\left.F_{(0.05,1} d f_{\text {error }}\right)$ is the F-ratio required for $95 \%$ confidence interval, $d f_{\text {error }}$ and $d f_{\text {total }}$ are the degrees of freedom of error and total associated with estimate of mean optimum, respectively, $M S S_{\text {error }}$ is the mean sum of squares of the error, $N$ is the total number of experiments, and $R$ is the number of trials for the confirmation experiment

\section{Testing feasibility of using ginger washing-} cum-peeling machine

The ginger washing-cum-peeling machine was tested for its feasibility in the production line of bleached ginger. Production of bleached ginger requires complete peeling. The ginger washing-cum-peeling machine was used for one hour for washing and rough peeling of fresh harvested ginger. Output capacity of the machine was determined. Labour and electrical energy requirement for washing and peeling $100 \mathrm{~kg}$ clean rough peeled ginger rhizomes was calculated. The rough peeled rhizomes were completely peeled by experienced labourers. The labour 
requirement for complete peeling of rhizomes was noted down.

Cost of mechanical washing and complete peeling of ginger rhizome was determined. Initial cost of the prototype machine was calculated by adding together the cost of raw materials used for fabrication, price of electric motor and the centrifugal pump, and labour charges for the fabrication. Initial cost of ginger washing-cum-peeling machine was INR 46000. Cost of operation included fixed cost and variable cost (Singh, 2017). Fixed cost included depreciation, interest on capital, insurance and taxes, and shelter cost. Variable cost included the cost of electric energy consumption, lubrication cost, repair and maintenance cost, and labour charges for the operation of machine and complete manual peeling of rough peeled rhizomes. The life of washing-cum-peeling machine was estimated to be 10 years. The annual rate of depreciation, interest on capital, insurance and taxes, housing, and repair and maintenance were assumed to be 10,12, 2, 1 and $10 \%$ of the initial cost, respectively. The labour wages for the unskilled labourer was INR 280 per day (8 hours).

Cost of mechanical washing and complete peeling of ginger rhizome was compared with conventional manual washing and peeling. Graphical method was used to identify the minimum number of hours of annual use required to justify the use of the ginger washing-cum-peeling machine as a supplement to the conventional manual washing and peeling for the preparation of bleached dry ginger.

\section{Results and Discussion}

\section{Effect of machine operating parameters on performance indices}

Variation in observed washing efficiency, peeling efficiency and percent loss of edible material with holding time and batch size at the selected rotary speed of brush rollers is shown in Figure 5. Washing and peeling efficiencies and per cent loss of edible material increased with increase in holding time and rotary speed of brush rollers, and decreased with increase in batch size.

As the increase in washing and peeling efficiencies is accompanied by increase in loss of edible material, there exist a set of machine operating parameters that define the best trade off between maximizing washing and peeling efficiencies and minimizing the loss of edible material.

Peeling efficiency and percent loss of edible material were affected by main and interaction of rotary speed of brush rollers, batch size and holding time (Table 1). Washing efficiency was affected by main effect of rotary speed of brush rollers, batch size and holding time, and interaction of rotary speed of brush rollers $\times$ batch size and rotary speed of brush rollers $x$ batch size $x$ holding time.

F values associated with washing efficiency was highest for holding time indicating that the holding time had the highest influence on washing efficiency.

The rotary speed of brush rollers had the highest influence on peeling efficiency and percent loss of edible material.

The interaction of rotary speed of brush rollers $\times$ batch size $\times$ holding time had the significant effect on all three performance indices. Hence, no one combination of machine operating parameters can satisfy the objective of maximizing washing and peeling efficiencies and minimizing the loss of edible material. Hence, a set of machine operating parameters was identified by non-dominated sorting technique that defines best trade off among the competing requirements. 
Best combination of machine operating parameters for ginger washing-cum-peeing machine

The non-dominated set of combination of machine operating parameters of the ginger washing-cum-peeling machine is shown in Table 2. Any one of the combinations of machine operating parameters can be taken. Rotary speed of $200 \mathrm{rpm}$ of the brush rollers, batch size of $3.0 \mathrm{~kg}$ and holding time of 12 minutes was taken as the best machine operating parameters considering that this combination of machine operating parameters results in the output capacity of $15 \mathrm{~kg} / \mathrm{h}$ with almost complete washing $(99 \%$ washing efficiency), $58 \%$ peeling and less than $2 \%$ loss of edible material $(1.92 \%$ loss of edible material).

The average values of washing efficiency (99\%), peeling efficiency (58\%) and percent loss of edible material $(1.92 \%)$ were used for the determination of $95 \%$ confidence interval. Substituting $F_{(0.05,1,54)}=4.02 \quad$ (from statistical tables), $d f_{\text {total }}=26, M S S_{\text {error }}=0.092$, 0.439 and 0.015 for washing efficiency, peeling efficiency and percent loss of edible material, respectively (from Table 1 ),$N=81$, and $R=5, C I$ was $0.44,1.09$ and 0.18 for washing efficiency, peeling efficiency and percent loss of edible material, respectively. The $95 \%$ confidence interval for washing efficiency was $98.56-99.44 \%$, peeling efficiency was $56.91-59.09 \%$ and percent loss of edible material was $1.74-2.10 \%$.

\section{Performance of the ginger washing-cum- peeling machine}

Results of one hour continuous performance (confirmation experiments) conducted at the best settings of the machine operating parameters (rotary speed of $200 \mathrm{rpm}$ of the brush rollers, batch size of $3.0 \mathrm{~kg}$ and holding time of 12 minutes) is shown in Table 3 . The machine was operated continuously for one hour during confirmation test, and $10 \%$ sample of output was collected for the determination of performance indices. On an average, $98.57 \%$ washing efficiency, $58.97 \%$ peeling efficiency and $1.91 \%$ loss of edible material was observed. The observed performance indices were within the range of the $95 \%$ confidence interval. This validated that the continuous operation of the ginger washing-cum-peeling machine for one hour do not significantly affect the performance of the machine.

A sample of the ginger rhizomes when fed to the machine and the same after mechanical washing and peeling are shown in Figure 6 . The machine removed all the soil from the rhizomes. It removed the peels only from the flat top and bottom surfaces. It did not remove peels from the curved surfaces, sides of the rhizomes and in between fingers of the rhizomes. However, quality of rough peeling was satisfactory for the production of rough peeled dry ginger.

\section{Results of feasibility test in the production line of bleached ginger}

The output capacity of the ginger washingcum-peeling machine was $15 \mathrm{~kg}$ fresh harvested ginger rhizomes per hour or 13.86 $\mathrm{kg}$ rough peeled ginger rhizomes per hour. Operation of the machine required one unskilled labourer. Labour requirement for washing and rough peeling of $100 \mathrm{~kg}$ rhizomes was 7.21 man-h. Electric current requirement by the 3-phase induction motor and single phase electric motor for $230 \mathrm{~V}$ supply was $7 \mathrm{~A}$ and $2.5 \mathrm{~A}$, respectively. Electrical energy consumption for washing and rough peeling of $100 \mathrm{~kg}$ rhizomes by 3 phase induction motor was $17.10 \mathrm{~kW}-\mathrm{h}$ and single phase electric motor was $3.53 \mathrm{~kW}-\mathrm{h}$. Labour requirement for the complete peeling of rough peeled rhizomes was found to be 7 man-h per hour of machine output (including $20 \%$ time loss). 
Table.1 Analysis of variance of washing and peeling efficiencies and percent loss of edible material

\begin{tabular}{|c|c|c|c|c|c|c|c|}
\hline \multirow[t]{2}{*}{ Source } & \multirow[t]{2}{*}{ df } & \multicolumn{2}{|c|}{$\begin{array}{l}\text { Washing } \\
\text { efficiency }\end{array}$} & \multicolumn{2}{|c|}{ Peeling efficiency } & \multicolumn{2}{|c|}{$\begin{array}{l}\text { Percent loss of } \\
\text { edible material }\end{array}$} \\
\hline & & MSS & $\mathrm{F}$ & MSS & $\mathrm{F}$ & MSS & $\mathrm{F}$ \\
\hline $\begin{array}{l}\text { Rotary speed of brush } \\
\text { rollers }(\mathrm{N})\end{array}$ & 2 & 23.21 & $252.02 * *$ & 2420.73 & $5510.75^{* *}$ & 226.03 & $14866.53^{* *}$ \\
\hline Batch size $(W)$ & 2 & 10.64 & $115.52 * *$ & 535.07 & $1218.09 * *$ & 20.41 & $1342.47 * *$ \\
\hline Holding time (T) & 2 & 36.62 & $397.70 * *$ & 1405.56 & $3199.73^{* *}$ & 36.37 & $2392.14^{* *}$ \\
\hline $\mathbf{N} \times \mathbf{W}$ & 4 & 0.85 & $9.21 * *$ & 13.93 & $31.72 * *$ & 6.49 & $426.93 * *$ \\
\hline $\mathbf{N} \times \mathbf{T}$ & 4 & 0.17 & $1.83^{\mathrm{NS}}$ & 58.80 & $133.86^{* *}$ & 12.35 & $811.99 * *$ \\
\hline $\mathbf{W} \times \mathbf{T}$ & 4 & 0.22 & $2.38^{\mathrm{NS}}$ & 7.93 & $18.05^{* *}$ & 0.55 & $35.93^{* *}$ \\
\hline $\mathbf{N} \times \mathbf{W} \times \mathbf{T}$ & 8 & 0.62 & $6.70 * *$ & 2.53 & $5.76^{* *}$ & 0.44 & $29.12 * *$ \\
\hline Error & 54 & 0.09 & & 0.44 & & 0.02 & \\
\hline
\end{tabular}

$* *=\mathrm{P}<0.01, \quad \mathrm{NS}=$ Non significant

Table.2 Non-dominated set of machine operating parameters of the ginger washing-cum-peeling machine

\begin{tabular}{|c|c|c|c|c|c|c|}
\hline \multicolumn{3}{|c|}{ Machine operating parameters } & \multicolumn{3}{|c|}{ Performance indices } & \multirow{2}{*}{$\begin{array}{l}\text { Number of } \\
\text { parameters } \\
\text { dominated }\end{array}$} \\
\hline $\begin{array}{l}\text { Rotary speed of } \\
\text { brush rollers, } \\
\text { rpm }\end{array}$ & $\begin{array}{l}\text { Batch } \\
\text { size, } \\
\text { kg }\end{array}$ & $\begin{array}{l}\text { Holding } \\
\text { time, } \\
\text { min }\end{array}$ & $\begin{array}{c}\text { Washing } \\
\text { efficiency, } \\
\%\end{array}$ & $\begin{array}{c}\text { Peeling } \\
\text { efficiency, } \\
\%\end{array}$ & $\begin{array}{c}\text { Percent loss of } \\
\text { edible material, } \\
\%\end{array}$ & \\
\hline 200 & 3 & 12 & 99.00 & 58.00 & 1.92 & 6 \\
\hline 200 & 3.5 & 16 & 99.00 & 58.00 & 2.00 & 5 \\
\hline 200 & 4 & 16 & 98.00 & 54.00 & 1.75 & 5 \\
\hline 150 & 4 & 12 & 97.00 & 47.00 & 1.20 & 4 \\
\hline 200 & 3.5 & 12 & 98.00 & 53.00 & 1.70 & 4 \\
\hline 200 & 3 & 16 & 100.00 & 64.00 & 3.20 & 3 \\
\hline 150 & 3 & 16 & 98.00 & 58.00 & 2.90 & 2 \\
\hline 150 & 3.5 & 12 & 97.00 & 51.00 & 1.60 & 2 \\
\hline 200 & 4 & 12 & 97.00 & 49.00 & 1.50 & 2 \\
\hline 150 & 3 & 8 & 96.80 & 47.00 & 1.50 & 1 \\
\hline 150 & 3 & 12 & 97.50 & 53.00 & 1.80 & 1 \\
\hline 150 & 3.5 & 16 & 98.00 & 54.00 & 2.30 & 1 \\
\hline 200 & 4 & 8 & 96.00 & 43.00 & 1.20 & 1 \\
\hline 250 & 4 & 12 & 98.00 & 63.00 & 4.70 & 1 \\
\hline
\end{tabular}

Table.3 Results of the confirmation experiments

\begin{tabular}{|l|c|c|c|c|c|c|}
\hline \multirow{2}{*}{\multicolumn{1}{|c|}{ Performance indices }} & \multicolumn{5}{|c|}{ Replications } & \multirow{2}{*}{ Mean } \\
\cline { 2 - 7 } & 1 & 2 & 3 & 4 & 5 & \\
\hline Washing efficiency, \% & 98.68 & 98.62 & 98.53 & 98.27 & 98.77 & 98.57 \\
\hline Peeling efficiency, \% & 59.07 & 56.33 & 55.62 & 59.69 & 64.12 & 58.97 \\
\hline Percent loss of edible material, \% & 1.80 & 1.36 & 3.15 & 1.76 & 1.50 & 1.91 \\
\hline
\end{tabular}


Figure.1 Isometric view ginger washing-cum-peeling machine

1. Washing tank

2. Perforated pipe

3. Sliding door

4. Outlet for washed and peeled rhizomes

5. Centrifugal Pump

6. Flexible pipe

7. Chain drive with idlers for brush rollers

8. Power transmission system

9. Electric motor

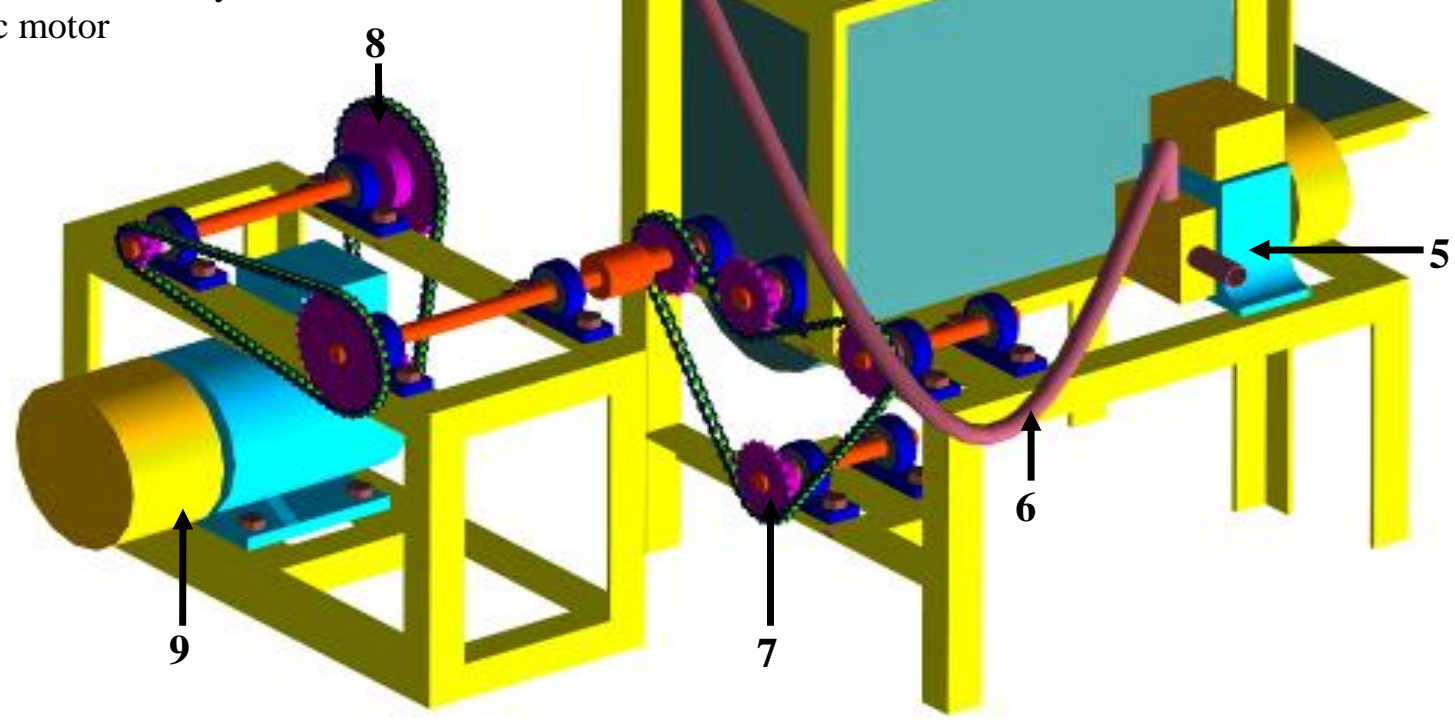

Figure.2 Arrangement of chain drive with idlers for brush rollers

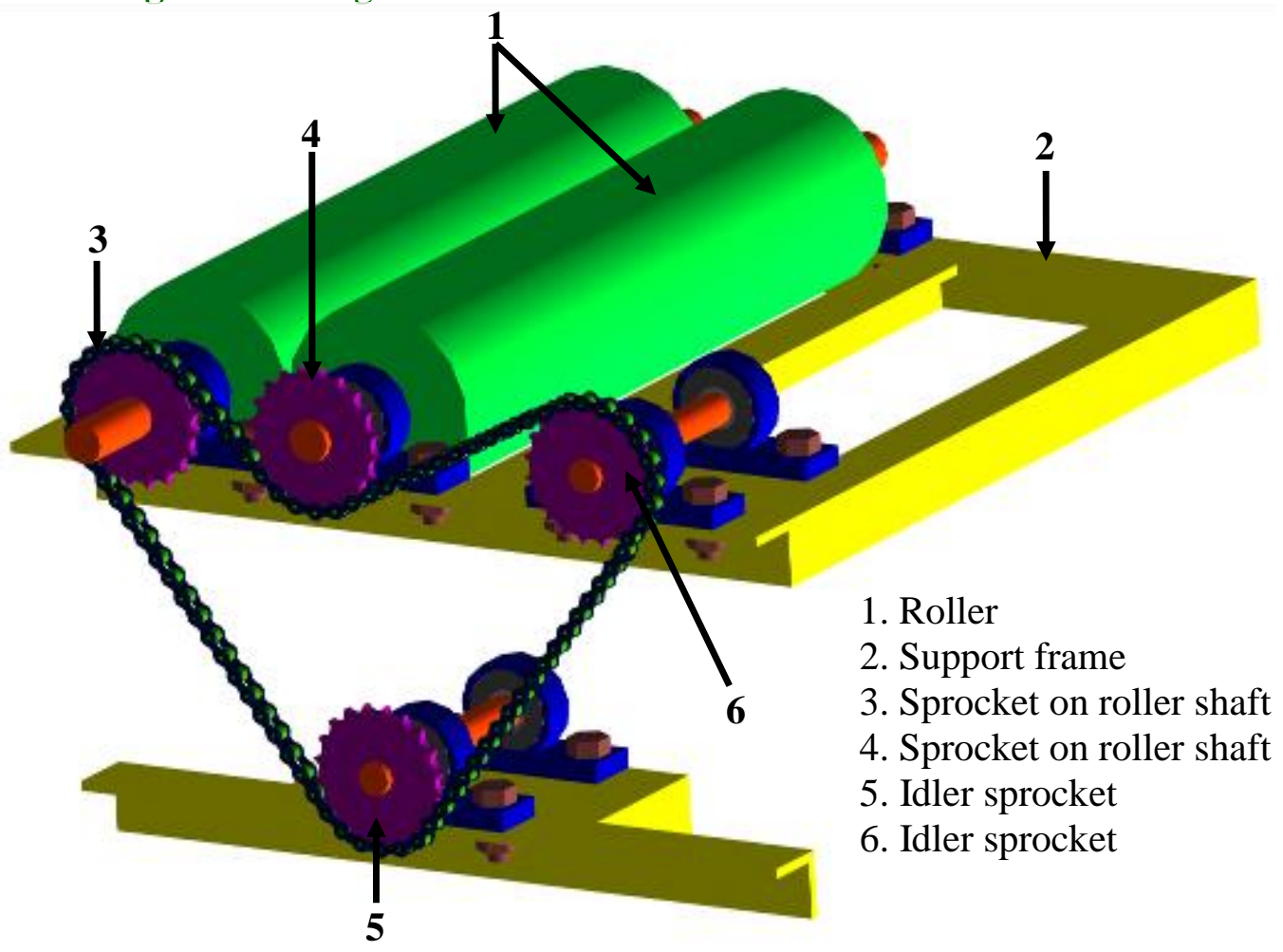


Figure.3 Overall view of prototype ginger washing-cum-peeling machine

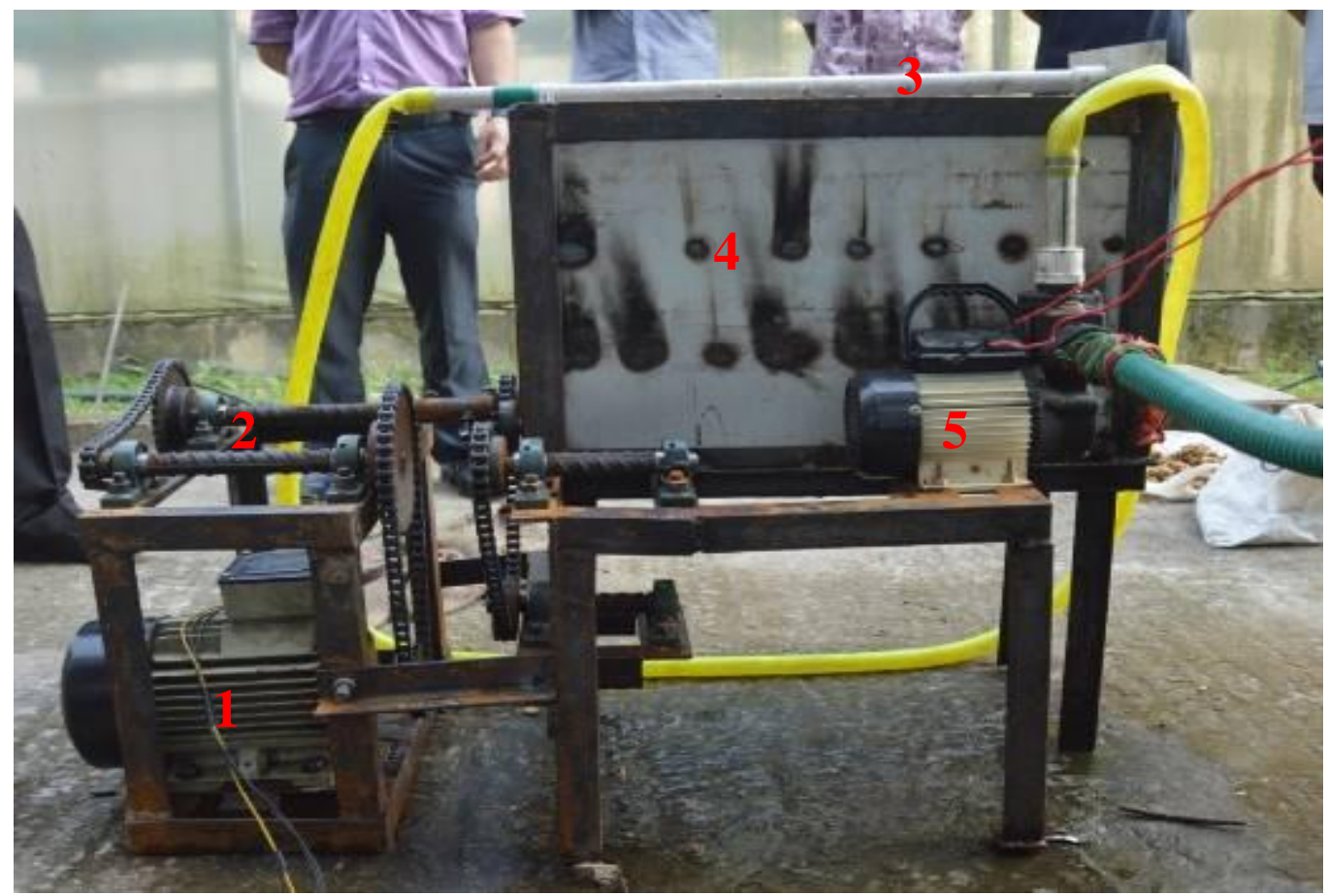

1. Electric motor 2. Power transmission system 3. Perforated pipe

4. Washing tank 5. Centrifugal pump

Figure.4 Inside view of washing tank

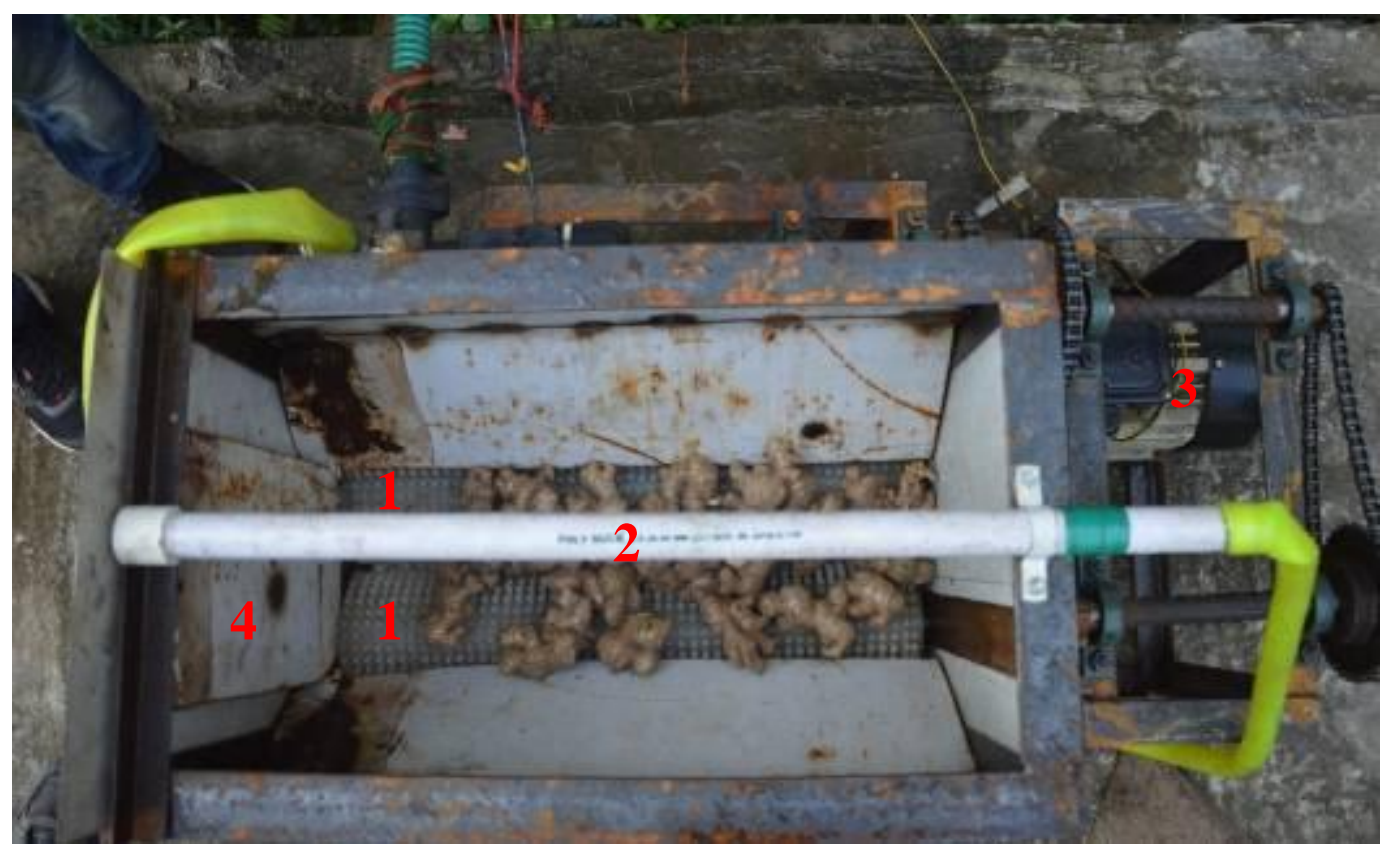

1. Brush rollers 2. Perforated pipe 3. Electric motor 4. Sliding door 
Figure.5 Variation in washing efficiency, peeling efficiency and percent loss of edible material with holding time and batch size at the selected rotary speed of brush rollers

Rotary speed of brush roller $=150 \mathrm{rpm}$ Rotary speed of brush roller $=200 \mathrm{rpm} \quad$ Rotary speed of brush roller $=250 \mathrm{rpm}$

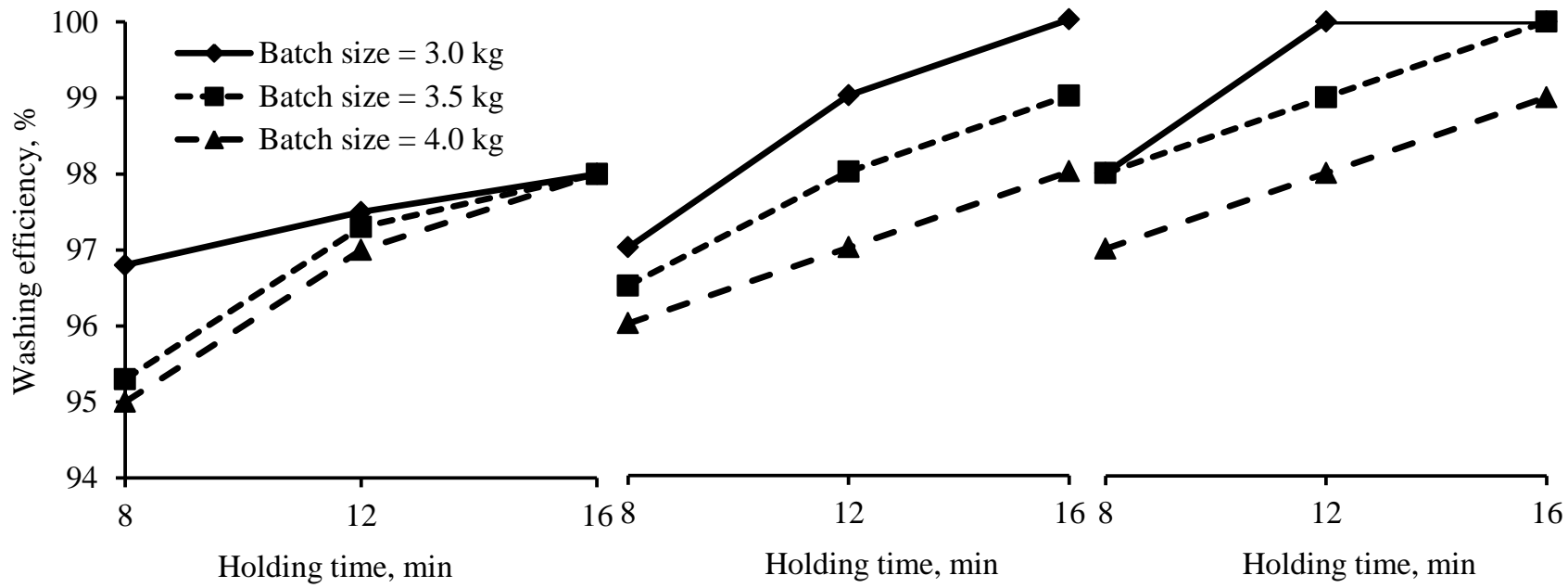

Rotary speed of brush roller $=150 \mathrm{rpm}$ Rotary speed of brush roller $=200 \mathrm{rpm} \quad$ Rotary speed of brush roller $=250 \mathrm{rpm}$

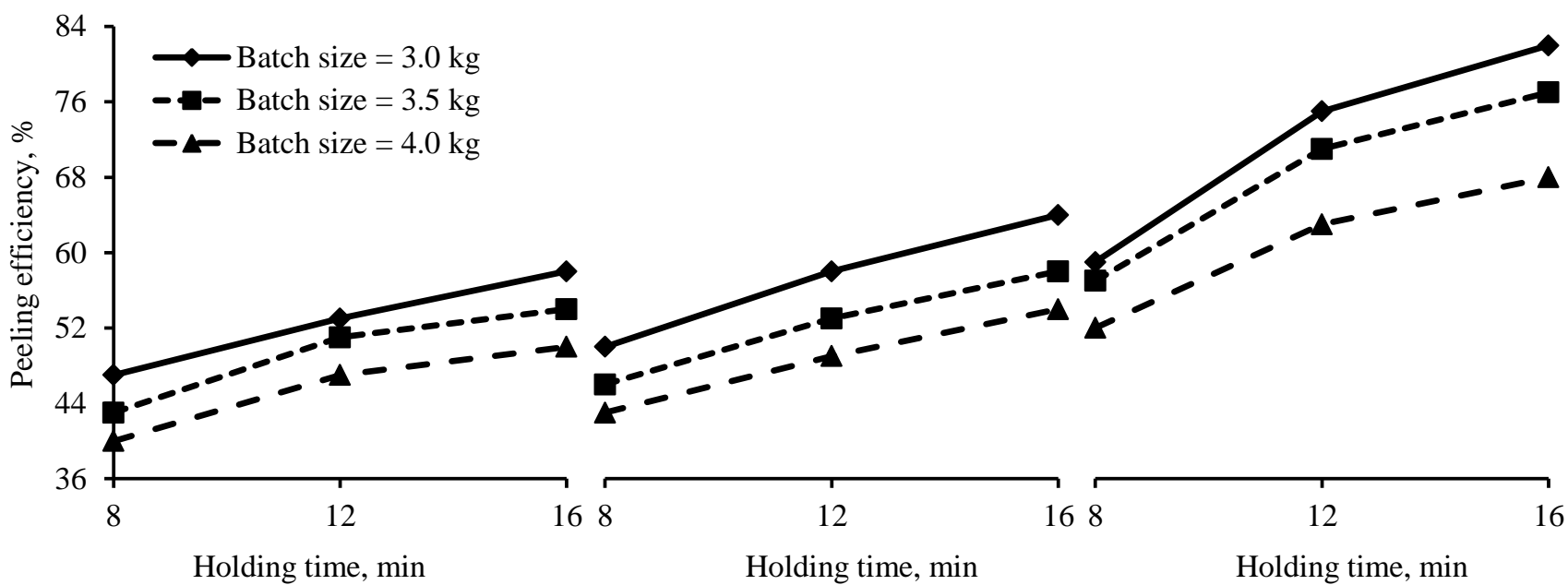

Rotary speed of brush roller $=150 \mathrm{rpm}$ Rotary speed of brush roller $=200 \mathrm{rpm} \quad$ Rotary speed of brush roller $=250 \mathrm{rpm}$

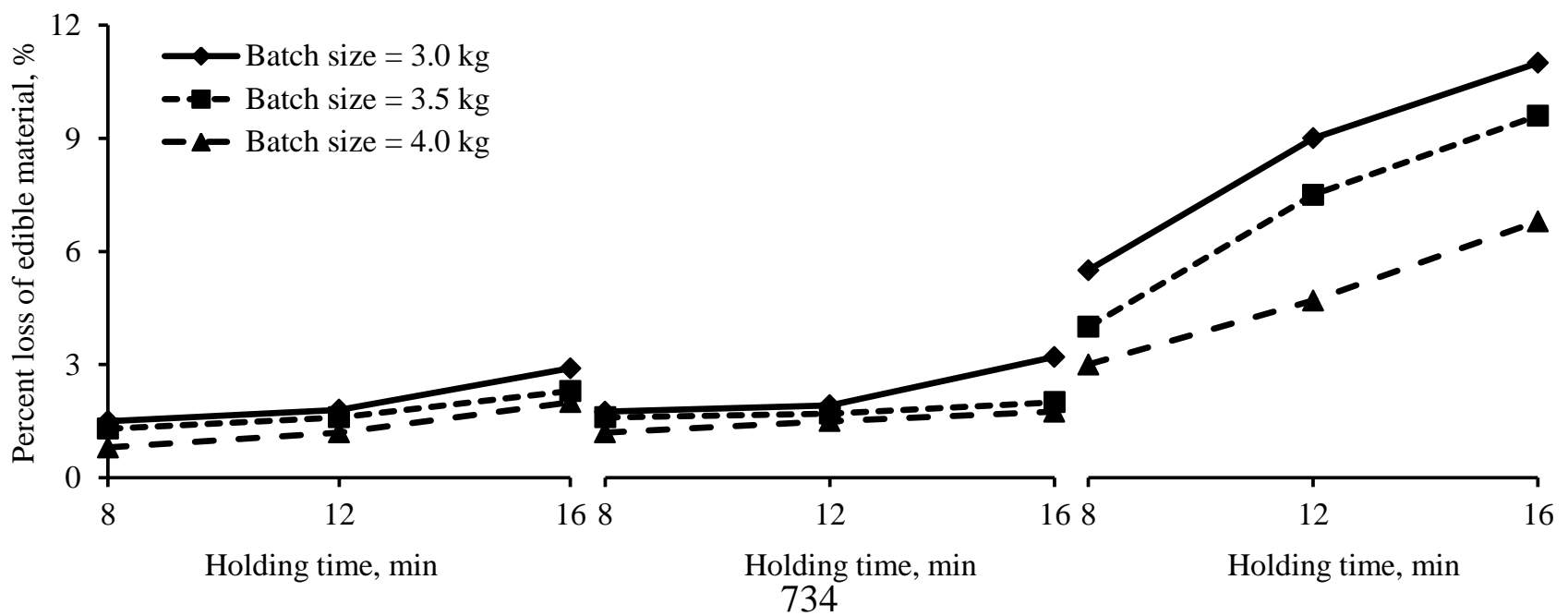


Figure.6 Sample of ginger rhizomes before feeding to the washing-cum-peeling machine, and after mechanical washing and rough peeling
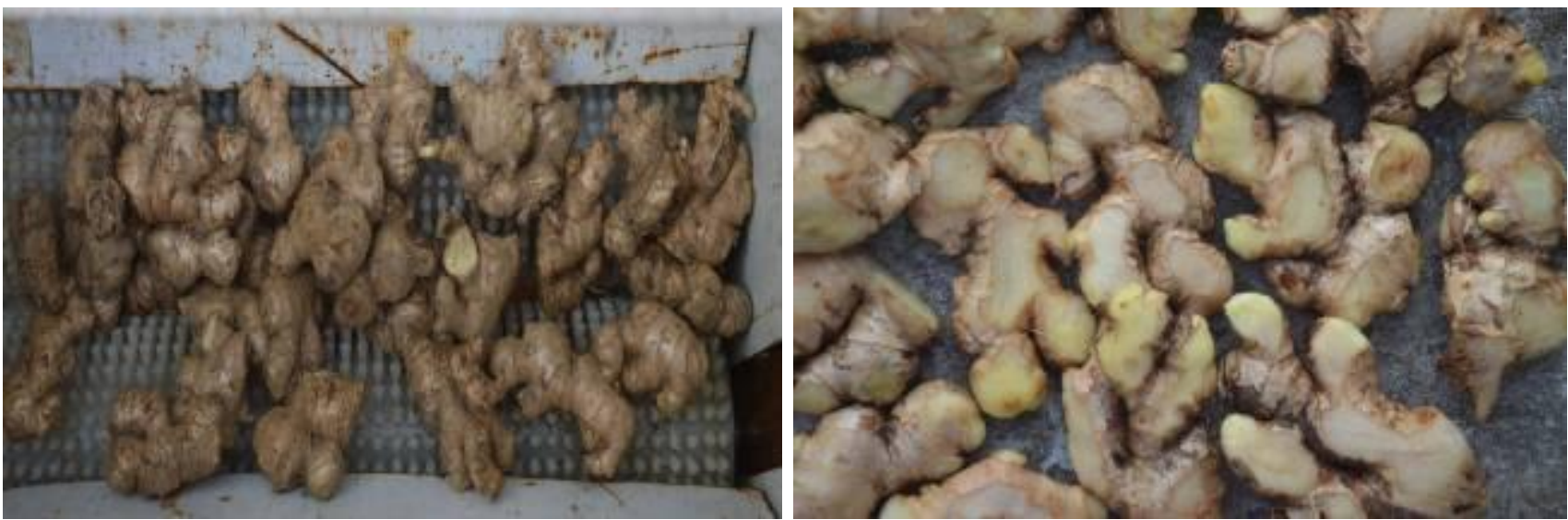

Figure.7 Comparison of cost of mechanical washing and complete peeling with manual washing and peeling of ginger rhizomes at various levels of annual use

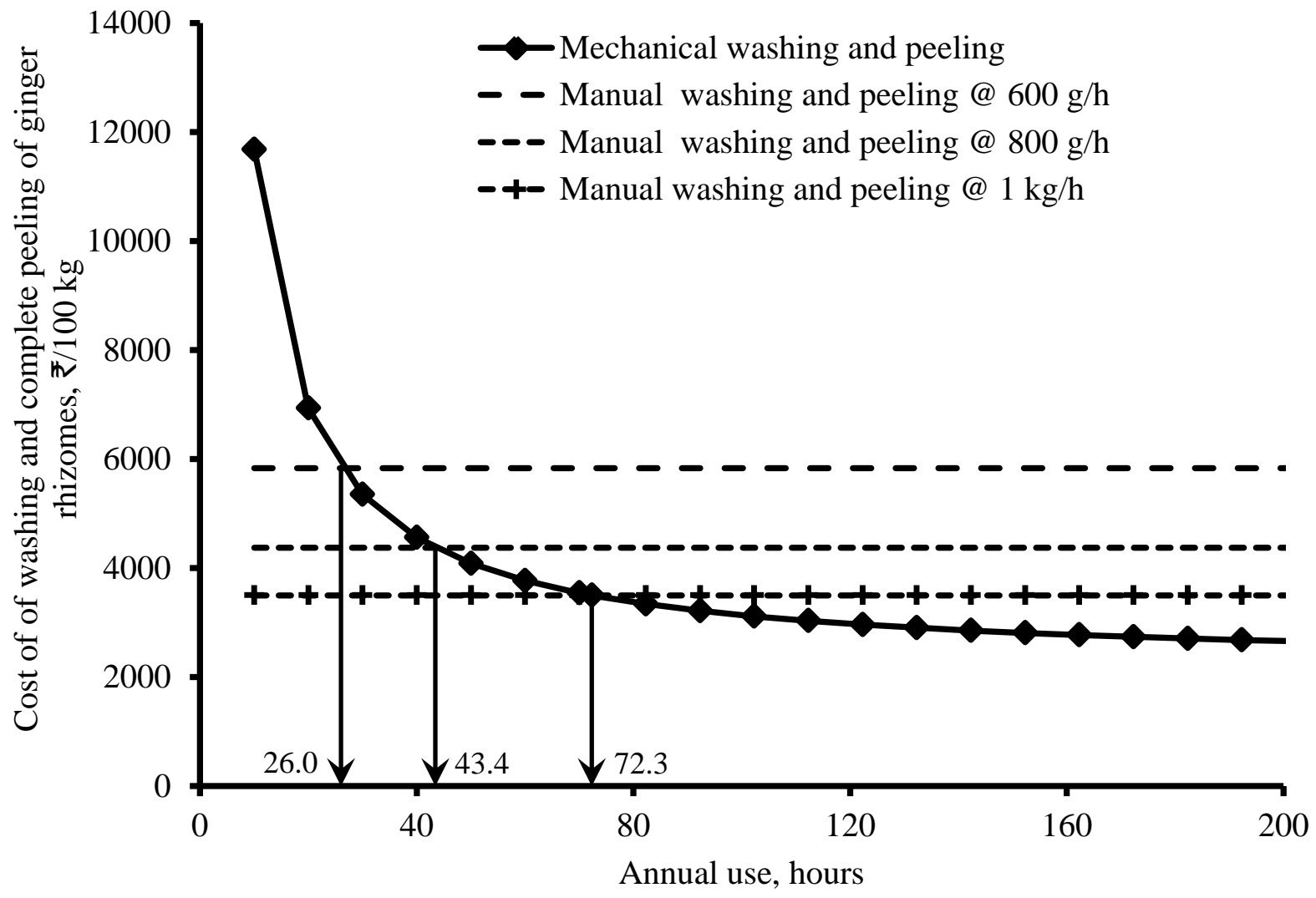

This amounts to labour requirement of 50.51 man-h/100 kg of machine output.
The cost of production of bleached ginger using washing-cum-peeling machine in the production line at various levels of annual use is shown in 
Figure 7. Cost of mechanical washing and peeling decreased with increase in annual use. Cost of manual washing and peeling at various rates of work output is also shown in Figure 7. Assuming output capacity of manual washing and peeling as 600,800 and $1000 \mathrm{~g} / \mathrm{h}$, cost of mechanical washing and peeling was similar to manual washing and peeling when the annual use of the machine was 26.0, 43.4 and 72.3 hours, respectively. This annual use refers to processing of 390, 651 and $1085 \mathrm{~kg}$ of fresh harvested ginger rhizomes per year. Ginger washing-cum-peeling machine can be recommended for use in small processing centres, commercial food centres and restaurants where the annual requirement of completely peeled ginger is more than $1010 \mathrm{~kg}$ or about $3.4 \mathrm{~kg} / \mathrm{day}$. This amount to operation of the machine for about one batch per day. Output capacity of the machine can be increased by increasing the length of the nylon brush rollers and applying water throughout the length of roller.

If the annual use of ginger washing-cumpeeling machine is 72 hours, cost of washing and complete peeling is INR 3500 per $100 \mathrm{~kg}$ fresh rhizomes. Total fixed cost, electricity charges, repair and maintenance cost and labour charges after the operation of machine for complete peeling of $100 \mathrm{~kg}$ rough peeled rhizomes was INR 853, INR 144, INR 460 and INR 1768, respectively. Total labour requirement for washing and complete peeling of $100 \mathrm{~kg}$ fresh rhizomes is 57.72 man-h. Use of machine improved the labour productivity. Mechanical washing and peeling by use of machine in the production line of bleached ginger resulted in the saving of $42.3 \%$ of labour and $46.7 \%$ time involved in manual washing and peeling of ginger rhizomes.

The peeled rhizomes were washed and dried in sun uniformly for one week. The dry rhizomes were rubbed together in order to get rid of the last bit of the skin or dirt. To get good appearance, peeled rhizomes were soaked in $2 \%$ limewater for 6 hours and then dried, and this is known as bleached dry ginger.
In conclusions, an electric motor powered batch type ginger washing-cum-peeling machine was developed. It had a washing tank, cylindrical brush rollers, water application system, and an electric motor and power transmission system. Fresh harvested ginger rhizomes were lifted and tumbled on the brush rollers rotating in opposite direction. The abrasive action of the roller brushes along with application of jet of water on the rhizomes completely washed and rough peeled the rhizomes. Performance indices were developed and the best operating parameters of the machine were identified by non-dominated sorting technique. A $200 \mathrm{rpm}$ rotary speed of the brush rollers, $3 \mathrm{~kg}$ of batch feeding of rhizomes and 12 minutes of holding time in the washing tank was found to be the best operating parameters of the machine that resulted in 98.57\% washing efficiency, $58.97 \%$ peeling efficiency and $1.91 \%$ loss of edible material. The output capacity of the machine was 13.86 $\mathrm{kg}$ rough peeled rhizomes per hour. Labour requirement for washing and rough peeling of $100 \mathrm{~kg}$ rhizomes was $7.21 \mathrm{man}-\mathrm{h}$. Total electrical energy consumption for washing and rough peeling of $100 \mathrm{~kg}$ rhizomes was 20.63 $\mathrm{kW}-\mathrm{h}$.

Ginger washing-cum-peeling machine developed had the potential to use in the production line of bleached dry ginger as supplement to manual washing and peeling. The machine can be recommended for use in small processing centres, commercial food centres and restaurants. Output capacity of the machine can be increased by increasing the length of the nylon brush rollers and applying water throughout the length of roller.

\section{References}

Agrwal, Y.C., Hiran, A. and Galundia, A.S. 1987. Ginger peeling machine parameters. Agricultural Mechanization in Asia, Africa and Latin America 18:5962.

Ambrose, D.C.P. and Annamalai, S.J.K. 2013. Development of a manually operated root crop washer. African Journal of 
Agricultural Research8: 3097-3101.

Antony, J. and Kaye, M. 2000. "Experimental Quality: A strategic Approach to Achieve and Improve Quality". Kluwer Academic Publishers, Dordrecht, The Netherlands.

Balakrishnan, K.V. 2005. Postharvest and industrial processing of ginger. In: "Ginger - The Genus Zingiber", (eds P.N. Ravindran and K.N. Babu), CRC Press, Boca Raton, Florida, USA.

BPS.2008. Philippine Agricultural Engineering Standards PAES 232:2008, Agricultural Machinery - Multicrop Washer-Peeler Specifications. Bureau of Product Standards. Manila, Philippine.

Choi, M., Han, I., Mohtashami, K., and Walker, K. 2014. "Design of A Small Scale Root Crop Washer". McGill University MacDonald Campus, Canada.

Deb, K., Pratap, A., Agarwal, S. and Meyarivan, T. 2002. A fast and elitist multiobjective genetic algorithm: NSGAII. IEEE Transactions on Evolutionary Computation6: 182-197.

Emers, M. 2012. "Barrel Washer for Cleaning Root Crops, Alaska Agricultural Innovation Grant Report 2012”. Department of Natural Resources, Alaska, USA.

Ghuman. R.S., Khanna, R., Singla, S., Singh, P. and Singh, H. 2014. Designing and fabrication of automatic root crop washer. International Journal of Research in Mechanical Engineering \& Technology. 4: 222-224.

Govindarajan, V.S. 1982. Ginger - chemistry, technology, and quality evaluation: Part 1.Critical Reviews in Food Science and Nutrition 17: 1-96.
IISR. 2015. Ginger, Extension Pamphlet. ICAR-Indian Institute of Spices Research. Kozhikode, Kerala, India.

Jayashree, E. and Viswanathan, R. 2012. Development of hand-operated mechanical ginger peeler. Journal of Horticultural Sciences 7: 75-80.

Peter, K.V. and Zachariah, T.J. 2000. Spice oils and oleoresins: Challenges and opportunities. Journal of Medicinal and Aromatic Plant Sciences22: 247-252.

Pruthi, J.S. 1992. Postharvest technology of spices: pre-treatments, curing, cleaning, grading and packing. Journal of Spices and Aromatic Crops 1: 1-29.

Singh, T.P. 2017. "Farm Machinery". PHI Learning Pvt. Ltd., Delhi, India.

Srinivasan, V., Shiva, K.N. and Kumar, A. 2008. Ginger. In: “Organic Spices”, (eds. V.A. Parthasarathy, K. Kandiannan and V. Srinivasan), New India Publishing, Delhi, India.

Sutarno, H., Hadad, E.A., and Brink, M. 1999. Zingiber officinale Roscoe. In: "Plant Resources of South-East Asia", No. 13, (eds. Guzman and J.S. Siemonsma), Backhuys Publishers, Leiden, The Netherlands.

Villamor, C.C. 2012. Micropropagation techniques for ginger, Zingiber officinale Rosc., an important medicinal plant. $E$ International Scientific Research Journal4: 241-249.

Weiss, E.A. 2002. “Spice Crops”.CAB International Publishing, Oxon, UK.

Zachariah T.J. 1999. Ginger. In: "Chemistry of Spices", (eds. V.A. Parthasarathy, B. Chempakam and T.J. Zachariah), CAB International, Wallingford, pages 79-96.

\section{How to cite this article:}

Prasanna Kumar, G.V., C.B. Khobragade, Rakesh Kumar Gupta and Kamran Raza. 2019. Development and Performance Evaluation of an Electric Motor Powered Ginger Washing-CumPeeling Machine. Int.J.Curr.Microbiol.App.Sci. 8(02): 722-737. doi: https://doi.org/10.20546/ijcmas.2019.802.084 